\title{
MORFOANATOMÍA DEL TALLO CON CRECIMIENTO SECUNDARIO DE ESPECIES DE JATROPHA (EUPHORBIACEAE) NATIVAS DE LA REGIÓN CHAQUEÑA ARGENTINA Y SU RELACIÓN CON EL AMBIENTE
}

\author{
Valeria Mansilla*, Alejandra Malbrán Barros, Verónica A. Cabrera (iD) \& Marisa Matesevach
}

Laboratorio de Morfología Vegetal, Facultad de Ciencias Exactas, Físicas y Naturales, Universidad Nacional de Córdoba, Av. Vélez Sarsfield 299, 5000 Córdoba, Argentina; valeriamns_34@hotmail.com (*autora corresponsal).

\begin{abstract}
Mansilla, V.; A. Malbrán Barros, V. A. Cabrera \& M. Matesevach. 2021. Morphoanatomy of the stem with secondary growth of Jatropha (Euphorbiaceae) species native to the Argentinian Chaco Region and its relationship with the environment. Darwiniana, nueva serie 9(1): 75-94.
\end{abstract}

Jatropha (Euphorbiaceae) is a morphologically diverse genus with pantropical distribution. It includes 180 species growing worldwide and has a broad range of uses: medicinal, ornamental and biodiesel production. In Argentina there are ten native species, distributed from the north to the center of the country, and one adventitious. However, the morphoanatomy of the native species of Jatropha is scarcely known, and so far, no anatomical studies of the stem with secondary growth have been performed in any of the native species. In this work, we analyzed the anatomy of the stem with secondary growth of three native species: J. excisa, J. hieronymi and J. macrocarpa, considering aspects related to the arid environment in which plants live, to provide information that it is useful for their conservation and possible sustainable use. Woody branches of each species were collected and fixed to perform temporary histological preparations of transverse and longitudinal sections of stems. We described their morphoanatomy under a light microscope. The following variables were analyzed: xylem area/ total area of the stem, number of vessels per $\mathrm{mm}^{2}$, vessel diameter and length of conductive elements. Indices were obtained to assess the drought vulnerability, the plant mesomorphy degree and to determine vessel clustering. The stems analyzed have several anatomical characters that are typical of plants that inhabit xerophytic environments, and that favor their development despite the scarce rainfall and high temperatures, including: suber and phelodermis with thickened cell walls; inner cortex with various cell layers; presence of chollenchyma; presence of chlorenchyma; ergastic substances in the cortex, vascular tissues and medullary parenchyma (latex, crystals and starch granules); short, narrow, numerous and grouped xylem vessels. The evaluated indexes suggest that the three taxa have a safe and efficient conduction system for water movement, being $J$. macrocarpa the most drougth resistant. This study provides novel information about these three species of biological, industrial, and economic importance, which are potential sources for biodiesel production.

Keywords. Chaco region; environment; Jatropha; morphoanatomy; stem; xerophyte.

Resumen. Mansilla, V.; A. Malbrán Barros, V. A. Cabrera \& M. Matesevach. 2021. Morfoanatomía del tallo con crecimiento secundario de especies de Jatropha (Euphorbiaceae) nativas de la Región Chaqueña Argentina y su relación con el ambiente. Darwiniana, nueva serie 9(1): 75-94.

El género Jatropha (Euphorbiaceae) es morfológicamente diverso y posee una distribución pantropical. Cuenta con unas 180 especies que crecen en todo el mundo y tienen una amplia gama de usos: medicinales, ornamentales y para producir biodiesel. En la Argentina, habitan diez especies autóctonas, distribuidas desde el norte al centro del país, y una adventicia. Poco se conoce sobre la morfoanatomía de las especies nativas y, hasta el momento, no se han realizado estudios sobre la estructura del tallo con crecimiento secundario en ninguna de ellas. En este trabajo, se analizó la morfoanatomía del tallo con crecimiento secundario de J. excisa, J. hieronymi y J. macrocarpa, considerando aspectos relacionados 


\begin{abstract}
con el ambiente árido en el que habitan, a fin de aportar información que sea útil para su conservación y el posible uso sustentable de los taxones. Se colectaron y fijaron ramas leñosas, a partir de las cuales se realizaron preparados histológicos temporarios de cortes transversales y longitudinales. Se describió la morfoanatomía y se calcularon las siguientes variables, que fueron analizadas estadísticamente: área del xilema/área total del tallo, número de vasos por $\mathrm{mm}^{2}$, diámetro y longitud de los vasos. Se obtuvieron índices para evaluar la vulnerabilidad a la sequía, el grado de mesomorfia de las plantas y el agrupamiento de los vasos. El tallo de las especies analizadas, presenta ciertos caracteres anatómicos que son propios de plantas que habitan en ambientes xerofíticos, y que en conjunto, contribuyen a que las mismas puedan desarrollarse a pesar de las escasas precipitaciones y elevadas temperaturas, incluyendo: súber y felodermis con paredes celulares engrosadas; corteza interna con varios estratos celulares; presencia de colénquima; presencia de clorénquima; sustancias ergásticas en corteza, tejido vascular y médula (látex, cristales y granos de almidón); vasos xilemáticos cortos, estrechos, numerosos y agrupados. Los índices evaluados sugieren que los taxones poseen un sistema de conducción seguro y eficaz para el movimiento del agua; se destaca J. macrocarpa por ser la más resistente a la sequía. Este estudio de anatomía ecológica brinda información novedosa sobre tres especies de importancia biológica, industrial y económica, que son potenciales productoras de biodiesel.
\end{abstract}

Palabras claves. Ambiente; Jatropha; morfoanatomía; región chaqueña; tallo; xerófito.

\section{INTRODUCCIÓN}

El género Jatropha L. (Euphorbiaceae) posee una distribución pantropical, con más de 100 especies en América, 70 en África y Arabia, y cuatro en la India (Fernández Casas, 2016). Las plantas son utilizadas en la medicina folklórica tradicional para curar diversas enfermedades, así como ornamentales y como cultivos energéticos, debido a las propiedades de sus semillas para la obtención de biodiesel (Sharma \& Singh, 2012). Dado que la demanda mundial de biodiesel ha aumentado en los últimos años, el interés por nuevos cultivos oleaginosos se ha incrementado notablemente. Varios autores estudiaron la producción de este biocombustible obtenido a partir de especies de Jatropha y analizaron las formas de cultivo, el área geográfica óptima para el desarrollo agroforestal, el contenido y calidad de aceite de las semillas, la conversión de aceites a subproductos, etc. (Achten et al., 2008; Falasca \& Ulberich, 2008; Aranda Rickert et al., 2011; Wassner et al., 2012). La especie más estudiada en este sentido a nivel mundial es Jatropha curcas L., y los trabajos realizados revelan que la calidad del biocombustible obtenido a partir de los extractos de sus semillas cumple con los estándares mínimos, tanto europeos como americanos, requeridos para su utilización. Teniendo en cuenta el aprovechamiento económico de $J$. curcas, se están impulsando estudios a lo largo del mundo con el objetivo de ampliar el conocimiento respecto de otras especies del género (Aranda Rickert et al., 2011; Wassner et al., 2012). Por ejemplo, en Argentina, el Instituto Nacional de Tecnología Agropecuaria (INTA), ha desarrollado un proyecto específico sobre Jatropha en el marco del Programa Nacional de Bioenergía (Consejo Agropecuario del Sur, 2009).

En la Argentina, habitan diez especies autóctonas distribuidas desde el norte al centro del país: Jatropha breviloba (Morong) Pax \& K. Hoffm., J. excisa Griseb., J. gossypiifolia L., $J$. grossidentata Pax \& K. Hoffm., J. hieronymi Kuntze, J. hippocastanifolia Croizat, J. isabelliae Müll. Arg., J. macrocarpa Griseb., J. pedersenii Lourteig y $J$. peiranoi Lourteig \& O'Donell; además de $J$. curcas L. que es adventicia (Zuloaga et al., 2019; permanentemente actualizado en http://conosur.floraargentina.edu.ar). Jatropha breviloba, $J$. isabelliae y $J$. pedersenii, habitan en el noreste del país, dentro de la Provincia Fitogeográfica Paranaense, y están asociadas a ambientes húmedos; el resto de las especies nativas se distribuye en el noroeste del país, en las Provincias Fitogeográficas Chaqueña, del Monte, de las Yungas y Prepuneña (Font, 2003). En la región Fitogeográfica Chaqueña, el clima es cálido, con escasas precipitaciones estivales en la zona occidental y predominancia de bosques caducifolios xerófitos (Cabrera, 1994). Allí, es frecuente encontrar a $J$. excisa, J. hieronymi y $J$. macrocarpa, en poblaciones que se distribuyen en parches de tamaño variable (Aranda Rickert, 2011). 
Estos taxones poseen hábito arbustivo, aunque $J$. hieronymi y $J$. macrocarpa pueden adoptar porte de árbol pequeño con el tiempo. Las tres especies son perennes, caducifolias, con hojas grandes y simples (lobuladas a palmadas), flores dispuestas en inflorescencias y frutos dehiscentes; su tallo es leñoso, con función de acumulación de reservas (Fernández Casas \& Pizarro Domínguez, 2007a; 2007b; Aranda Rickert, 2011). Se ha reconocido la potencialidad de las tres especies para la obtención de biodiesel, a partir del aceite de sus semillas, siendo $J$. macrocarpa la más estudiada en este sentido (Falasca \& Ulberich, 2008; Aranda Rickert et al., 2011; Clérici et al., 2013).

El estrés ambiental juega un papel importante en la evolución de las plantas; el rango de temperatura y la disponibilidad de agua se encuentran entre los principales factores que determinan el grado de especificidad en relación con el hábitat (Fahn \& Cutler, 1992). De acuerdo al ambiente donde los vegetales se desarrollan, serán diferentes las estrategias para optimizar y asegurar la conducción de agua (Moglia \& López, 2001; Montaño Arias et al., 2013). En lugares xerofíticos, la vegetación está sometida a radiación intensa, alternancia de temperaturas extremas, suelo pobre en nutrientes y baja disponibilidad de agua; todos estos factores llevan a cambios morfológicos, anatómicos y fisiológicos, que han permitido la evolución hacia formas vegetales aptas para crecer ante estas situaciones de déficit hídrico y altas temperaturas (Beltramini y Zapata, 2020). Las regiones que son secas y a la vez cálidas, ofrecen los ejemplos más claros de cómo el estrés hídrico influye en las características del xilema (Carlquist, 2001). El sistema xilemático de los vegetales que viven en ambientes secos está preparado para conducir la escasa cantidad de agua distribuida en un período anual determinado: posee vasos numerosos, agrupados y de diámetro pequeño, y elementos conductores de longitudes cortas; estas características confieren a las plantas una mayor seguridad y eficiencia en la conducción de agua, permitiendo resistir altas tensiones, disminuyendo el riesgo de embolia y otorgando resistencia al estrés hídrico (Fahn \& Cutler, 1992; Carlquist, 2001; Moglia \& López, 2001; León, 2005; Montaño Arias et al., 2013). La relación área de tejido xilemático/área total del tallo, también es un carácter anatómico que define la capacidad de transporte de agua. Se observa que en especies arbóreas, a medida que aumenta el área xilemática, la cantidad de agua transportada es mayor, y este carácter puede ser un indicador de mayor adaptación de las plantas a condiciones de baja humedad en el suelo (Sory Toure et al., 2010). Carlquist (1977) propuso índices para evaluar la vulnerabilidad a la sequía en plantas, el agrupamiento de los vasos y el grado de mesomorfía, que relaciona densidad, diámetro y longitud de los vasos. Estos índices permiten conocer la resistencia de las especies a bajas precipitaciones, principalmente en plantas que habitan en zonas secas. Además de las características del xilema, es posible identificar en los tallos otros caracteres anatómicos típicos de plantas xerófitas, como la presencia de tejidos reservantes, abundancia de tejidos de sostén (colénquima y esclerénquima) y de parénquima con cloroplastos, desarrollo temprano del cambium vascular y tejidos vasculares secundarios, entre otros (Pérez Cuadra \& Cambi, 2014; Beltramini \& Zapata, 2020).

Son pocos los trabajos realizados sobre la anatomía vegetativa de las especies nativas de Jatropha (Malbrán Barros et al., 2016; Tavecchio et al., 2016; Malbrán Barros et al., 2017; Malbrán Barros, 2018); los mismos se centran en aspectos de la estructura primaria, pero hasta el momento no se ha analizado el tallo con crecimiento secundario en ninguna de ellas. Teniendo en cuenta la falta de estudios anatómicos en estas especies nativas, y considerando su importancia como potenciales productoras de biodiesel, en este trabajo analizamos la morfoanatomía del tallo con crecimiento secundario de $J$. excisa, J. hieronymi y J. macrocarpa, considerando aspectos relacionados con el ambiente árido que habitan, a fin de aportar información que sea útil para su conservación y el posible uso sustentable de los taxones.

\section{MATERIALES Y MÉTODOS}

Área de estudio y colección de las muestras

Se trabajó con material colectado en las provincias de Catamarca, Santiago del Estero y Córdoba, en localidades pertenecientes al Distrito Chaqueño Occidental de la Provincia Fitogeográfica Chaqueña de Argentina (Cabrera, 1994). 
En dicha región, la precipitación media anual es de $500-800 \mathrm{~mm}$, con temperaturas máximas que superan $\operatorname{los} 45^{\circ} \mathrm{C}$, y mínimas por debajo de $0^{\circ} \mathrm{C}$; la vegetación está formada por bosques xerófitos, algunos palmares, estepas halófilas y sabanas edáficas o inducidas por incendios y desmontes (Cabrera, 1994; Giménez \& Moglia, 2003).

Durante noviembre de 2016, se visitaron 3 sitios para cada una de las especies y se muestrearon tres ejemplares adultos, de aspecto saludable, en cada sitio. Se trabajó con nueve individuos de cada especie. Con el fin de obtener caracterizaciones comparables, se utilizaron secciones de ramas de segundo y tercer orden (considerando primer orden al eje principal), de aspecto leñoso y 2-3 $\mathrm{cm}$ de diámetro, que fueron fijadas en una mezcla de formaldehído, alcohol y ácido acético (FAA) (Zarlavsky, 2014). Los ejemplares de referencia están depositados en el Herbario del Museo Botánico de Córdoba (CORD). Los ejemplares de referencia en cada sitio de colecta son:

\section{Jatropha excisa.}

ARGENTINA. Catamarca. Depto. Capital, Banda de Varela, $65^{\circ} 45^{\prime} 30,39^{\prime \prime} \mathrm{W}$ y $28^{\circ} 26^{\prime} 05,96^{\prime \prime} \mathrm{S}$, 578 m s.m., 21-XI-2016, Cosa et al. 435 (CORD); Camino a gruta de la Virgen del Valle, $65^{\circ} 47^{\prime} 80,97^{\prime \prime} \mathrm{W}$ y $28^{\circ} 25^{\prime} 18,87^{\prime \prime} \mathrm{S}, 635 \mathrm{~m}$ s.m., 21-XI- 2016, Cosa et al. 436 (CORD). Córdoba. Depto. Tulumba, RN 60, km 891, pasando Lucio V.

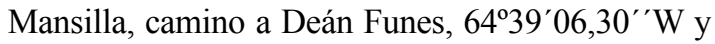
$29^{\circ} 52^{\prime} 99,50^{\prime \prime}$ S, 233 m s.m., 23-XI-2016, Cosa et al. 448 (CORD).

\section{Jatropha hieronymi.}

ARGENTINA. Santiago del Estero. Depto. Choya, RP 24, entrando $5 \mathrm{~km}$ a la Quebrada de Maquijata entre La Merced y Villa La Punta, $64^{\circ} 47^{\prime} 71,72^{\prime \prime} \mathrm{W}$ y $28^{\circ} 15^{\prime} 02,36^{\prime \prime} \mathrm{S}, 456 \mathrm{~m}$ s.m., $22-$ XI-2016, Cosa et al. 444 y 445 (CORD); RP 24, Villa La Punta cerca del Dique, 64\%48'04,10' 'W y $28^{\circ} 22^{\prime} 30,80^{\prime \prime} \mathrm{S}, 433 \mathrm{~m}$ s.m., 22-XI-2016, Cosa et al. 446 (CORD).

\section{Jatropha macrocarpa.}

ARGENTINA. Catamarca. Depto. Capital, RP 33, $18 \mathrm{~km}$ antes de San Fernando del Valle

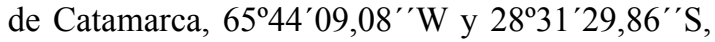
540 m s.m., 21-XI-2016, Cosa et al. 432 (CORD);

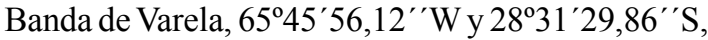
540 m s.m., 21-XI-2016, Cosa et al. 433 (CORD); Banda de Varela, 65 $45^{\prime} 67,61^{\prime \prime} \mathrm{W}$ y $28^{\circ} 26^{\prime} 01,36^{\prime \prime} \mathrm{S}$, 570 m s.m., 21-XI-2016, Cosa et al. 434 (CORD).

\section{Estudios morfoanatómicos del tallo}

Para los estudios exomorfológicos, se analizó tanto el material conservado, como el herborizado y los registros fotográficos in situ. Se describió el tallo según el color y la textura de la corteza, siguiendo el trabajo de Demaio et al. (2015). Para los estudios anatómicos se utilizaron ramas conservadas, de aproximadamente $2-3 \mathrm{~cm}$ de diámetro; se hicieron preparados histológicos temporarios a mano alzada, con una hoja de bisturí, realizando cortes transversales y longitudinales tangenciales, de 0,2 $\mathrm{mm}$ de espesor, aproximadamente. Se colorearon con azul astralfucsina básica (Kraus et al., 1998), se enjuagaron con agua destilada y se montaron con glicerina. Este procedimiento evita la deshidratación, y de esta forma las muestras no se modifican o agrietan (Wang \& Aitken, 2001). Las observaciones se realizaron con un microscopio óptico compuesto ZEISS Primo Star y se tomaron microfotografías con una cámara digital Nikon Coolpix S630. Para la clasificación de los laticíferos, se siguió a Dehgan \& Craig (1978).

\section{Variables xilemáticas analizadas}

A partir de los preparados histológicos de cortes transversales, se calculó:

- Área del xilema/área total del tallo (\%): se utilizaron fotografías de los preparados, que fueron analizadas con el programa ImageJ (Rasband, 2018), el cual permite conocer el área seleccionada de una imagen partiendo de una distancia conocida.

- Número de vasos por $\mathrm{mm}^{2}$ : se obtuvo usando un ocular con cuadrícula de $0,065 \mathrm{~mm}^{2}$ y contando todos los vasos presentes en seis campos por individuo (54 campos por especie), seleccionados al azar. Los vasos fueron considerados como extremadamente poco numerosos $(\leq 5$ vasos por $\mathrm{mm}^{2}$ ), poco numerosos (5-20 vasos por $\mathrm{mm}^{2}$ ), numerosos (20-40 vasos por $\left.\mathrm{mm}^{2}\right)$, muy numerosos (40-100 vasos por $\mathrm{mm}^{2}$ ) y extremadamente numerosos $\left(\geq 100\right.$ vasos por $\mathrm{mm}^{2}$ ) (Carlquist, 1977; IAWA Committee, 1989). 
- Diámetro de los vasos: se midió el diámetro de seis vasos por individuo (54 para cada especie), seleccionados al azar. El diámetro se consideró muy pequeño $(\leq 50 \mu \mathrm{m})$, pequeño $(50-100 \mu \mathrm{m})$, mediano $(100-200 \mu \mathrm{m})$ y grande $(\geq 200 \mu \mathrm{m})$ (Carlquist, 1977; IAWA Committee, 1989).

A partir de los preparados histológicos de cortes longitudinales tangenciales, se calculó:

- Longitud de elementos de vaso: se midió la longitud de seis elementos por individuo (54 para cada especie), seleccionados al azar. La longitud se consideró corta $(\leq 350 \mu \mathrm{m})$, mediana $(350-800 \mu \mathrm{m})$ y larga $(\geq 800 \mu \mathrm{m})$ (Carlquist, 1977; IAWA Committee, 1989).

\section{Índices analizados}

- Índice de vulnerabilidad (IV): se obtiene dividiendo la media del diámetro de los vasos por la media del número de vasos por $\mathrm{mm}^{2}$. Un índice mayor a uno indica vulnerabilidad a la sequía, y menor a uno demuestra resistencia (Carlquist, 1977).

- Índice de mesomorfía (IM): se calcula multiplicando la longitud media de los elementos de vaso por el IV. Un índice mayor a 200 representa un xilema mesofítico, y menor o igual a 75 significa que es xerofítico (Carlquist, 1977).

- Índice de agrupamiento de los vasos (IVg) : se obtiene dividiendo el número total de vasos por el número de grupos de vasos. Un índice igual a uno indica vasos exclusivamente solitarios, y a mayor índice, mayor es el grado de agrupamiento de vasos (Carlquist, 2001).

\section{Análisis estadísticos}

Para la variable "área del xilema/área total del tallo" se realizó un diseño completamente aleatorizado; para "número de vasos por $\mathrm{mm}^{2}$ ", "diámetro de los vasos" y "longitud de los elementos de vaso" se realizó un diseño con estructura anidada de tratamientos, donde el factor "Individuo" está anidado dentro del factor "Especie". Los datos cuantitativos obtenidos se sometieron a un análisis de la varianza (ANAVA), seguido por la prueba de LSD Fisher $(\mathrm{P} \leq 0.05)$. Previamente, se corroboró que se cumplieran los supuestos de normalidad y homogeneidad de la varianza. Los análisis se llevaron a cabo mediante el paquete estadístico Infostat (Di Rienzo et al., 2018).

\section{RESULTADOS}

\section{Exomorfología}

Los tallos de las tres especies son glabros, de color verde a marrón en $J$. excisa, y grisáceo en $J$. hieronymi y $J$. macrocarpa. En estas dos últimas especies, la corteza o ritidoma es transversalmente exfoliante, es decir, se desprende en escamas que se enrollan cuando el tallo supera los tres $\mathrm{cm}$ de diám.; esto no ocurre en J. excisa (Fig. 1A-C). En los sitios de abscisión de las hojas, hay cicatrices prominentes. En $J$. excisa, las cicatrices foliares tienen forma orbicular achatada en el lado adaxial, mientras que en $J$. hieronymi y $J$. macrocarpa son suborbiculares con una concavidad en el lado abaxial que termina en un apículo (Fig. 1D-F). Se observan lenticelas distribuidas irregularmente en $J$. excisa y $J$. hieronymi, mientras que en $J$. macrocarpa las mismas se disponen en pequeños grupos. En $J$. excisa las lenticelas son más abundantes, alargadas, paralelas al eje del tallo y blanquecinas; en $J$. hieronymi y $J$. macrocarpa, se observan circulares y parduzcas (Fig. 1G-I).

\section{Anatomía}

Los tallos presentan forma circular en sección transversal. En los individuos adultos analizados, se observa en sus ramas de aspecto leñoso, un crecimiento secundario en etapa temprana. De afuera hacia adentro, se reconocen los siguientes estratos: peridermis, corteza, tejidos vasculares y médula (Fig. 2A-C), que se describen a continuación.

Peridermis: conformada por 2-4 estratos de súber, felógeno superficial y 2-8 capas de felodermis; la felodermis está compuesta por células rectangulares, aplanadas tangencialmente, sin espacios intercelulares; tanto el súber como la felodermis presentan paredes celulares engrosadas. En $J$. hieronymi y $J$. macrocarpa es continua, mientras que no lo es en $J$. excisa, donde la epidermis uniestratificada aún persiste. En ese caso, las células epidérmicas propiamente dichas son rectangulares, con cutícula lisa y delgada (Fig. 3A-C).

Corteza interna: se compone de aproximadamente 40 estratos de células en $J$. excisa y $J$. hieronymi, y 60 en $J$. macrocarpa. 

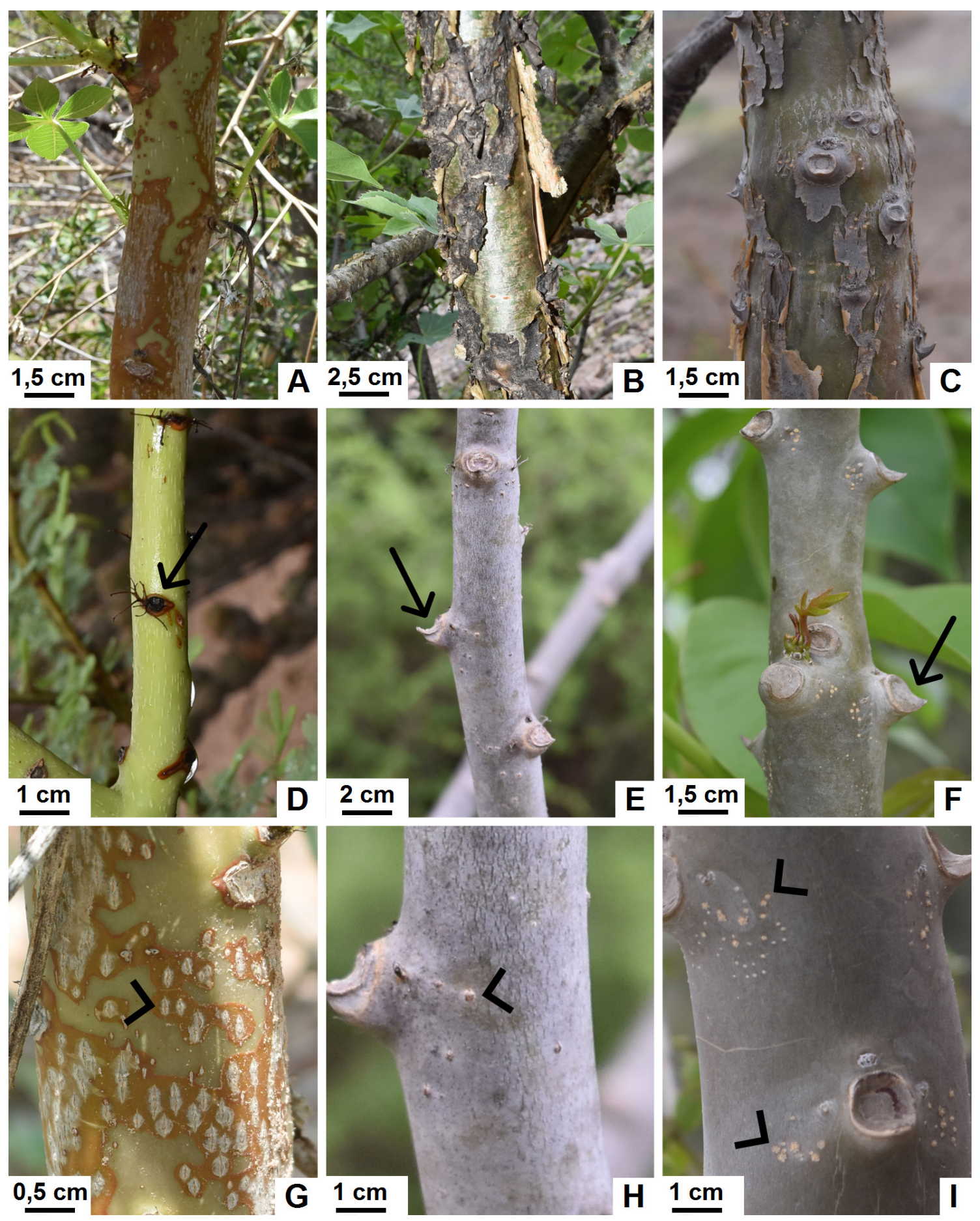

Fig. 1. Exomorfología del tallo con crecimiento secundario de especies nativas de Jatropha. A, ritidoma no exfoliante de J. excisa, en tallo principal. B-C, ritidoma exfoliante de J. hieronymi y J. macrocarpa, respectivamente, en tallo principal. D-F, cicatrices foliares de J. excisa, J. hieronymi y J. macrocarpa, respectivamente, en ramas de segundo y tercer orden. Las flechas señalan la ubicación de las cicatrices. G-I, lenticelas en J. excisa, J. hieronymi y $J$. macrocarpa, respectivamente, señaladas por punta de flecha. Figura en color en la versión en línea http:// www.ojs.darwin.edu.ar/index.php/darwiniana/article/view/906/1210 
Se distinguen 2-3 capas externas de colénquima lamelar; por debajo, hay 2-4 estratos discontinuos de colénquima angular en $J$. hieronymi y $J$. macrocarpa, y 4-8 capas continuas en J. excisa. Los primeros 5-6 estratos de parénquima, ubicados por debajo del colénquima, presentan cloroplastos. Por debajo del clorénquima, el parénquima cortical de las tres especies posee células redondeadas con paredes moderadamente engrosadas y espacios intercelulares pequeños (Fig. 3A-C). En J. hieronymi, se observan pequeños grupos de fibras en la corteza, los cuales están ausentes en las otras dos especies (Fig. 2B). Además, se evidencian fibras perivasculares en las tres especies, dichas agrupaciones son más grandes en $J$. excisa y $J$. hieronymi en relación a las de $J$. macrocarpa (Fig. 2A-C y 4A-C). Algunas células parenquimáticas poseen cristales (drusas y pequeños cristales prismáticos), otras acumulan gránulos de almidón, los cuales son comparativamente más abundantes en $J$. macrocarpa (Figs. 3A-Cy 4D-F). Hay abundantes laticíferos, principalmente en los estratos más próximos al floema, conteniendo látex de color pardo oscuro (Fig. 4A-D). En corte longitudinal tangencial, se observa que los laticíferos en $J$. macrocarpa son articulados no anastomosados, y no articulados, tanto ramificados como no ramificados. En J. excisa y J. hieronymi, además de los tres tipos mencionados, se evidenciaron también laticíferos articulados anastomosados (Fig. 5A-D).

Tejidos vasculares: evidencian una etapa temprana del crecimiento secundario, y se disponen en un anillo continuo de floema secundario, una zona cambial y un anillo continuo de xilema secundario (Fig. 2A-C). El floema consta de 6-10 estratos celulares; los radios parenquimáticos son uni o biseriados, aunque en $J$. macrocarpa, algunos se ensanchan, llegando a ser multiseriados. En las tres especies hay laticíferos en este tejido (Fig. 6A-C). En el xilema, la porosidad es difusa en las tres especies, con poros parcialmente solitarios y parcialmente agrupados en filas radiales; en los tres taxones se aprecian además, grupos pequeños de vasos que están en contacto entre sí por sus paredes radiales y tangenciales. Los radios parenquimáticos son uni y biseriados (Fig. 6D-F).
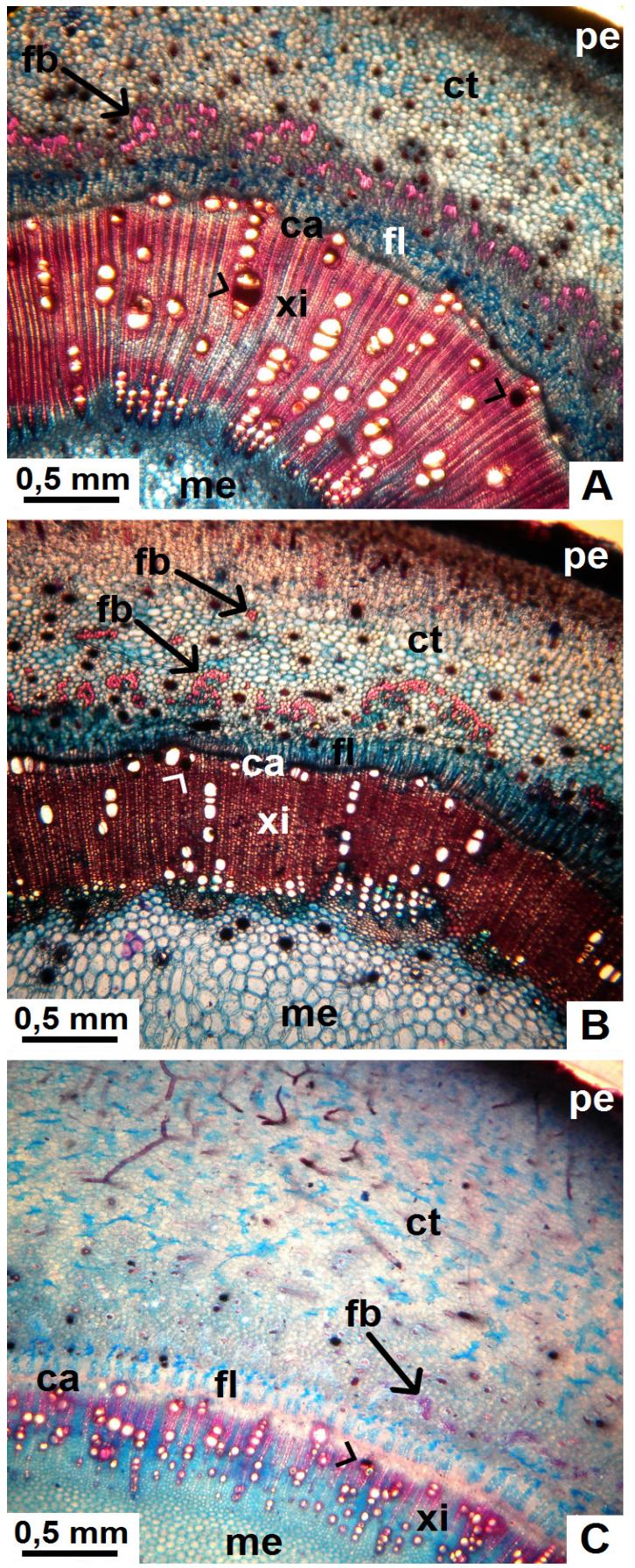

Fig. 2. Tallo con crecimiento secundario, en corte transversal de especies nativas de Jatropha. A, vista general de $J$. excisa. B, vista general de $J$. hieronymi. $\mathbf{C}$, vista general de $J$. macrocarpa. Abreviaturas: ca, zona cambial; ct, corteza; fb, fibras; fl, floema secundario; me, médula; pe, peridermis; xi, xilema secundario. Con punta de flecha se señalan vasos ocluidos. Figura en color en la versión en línea http://www.ojs. darwin.edu.ar/index.php/darwiniana/article/view/906/1210 
No se observó tilosis en ningún caso, pero en los tres taxones, algunos vasos aislados se encuentran ocluidos por una sustancia parda, presumiblemente taninos o gomas (Fig. 2A-C y Fig. 6B-C,E). El parénquima axial es de distribución apotraqueal; en $J$. excisa es agregado (Fig. 6D), mientras que en $J$. macrocarpa y J. hieronymi, se dispone como cordones entre los vasos y fibras, siendo difuso (Fig. 6E-F). En sección longitudinal tangencial, los elementos de vaso presentan punteaduras alternas, de contornos circulares a ovalados en sus paredes laterales; en los extremos, las paredes son oblicuas. Las fibras libriformes poseen paredes moderadamente engrosadas, y se encontraron además fibras septadas en las tres especies. Se observan granos de almidón tanto en las células del parénquima axial como en las células de los radios. Hay también traqueidas vasicéntricas, de paredes más finas (Fig. 7A-D).

Médula: formada por parénquima con células grandes, redondeadas a isodiamétricas, de paredes delgadas y con pequeños espacios intercelulares. En J. macrocarpa, se observan abundantes granos de almidón. Jatropha excisa y J. hieronymi poseen abundantes laticíferos, los cuales están ausentes en $J$. macrocarpa (Fig. 8A-C).

\section{Variables xilemáticas analizadas}

El xilema secundario de $J$. excisa y $J$. hieronymi presenta vasos numerosos $(27,63 \mathrm{y}$ 28,48 vasos por $\mathrm{mm}^{2}$, respectivamente), mientras que en $J$. macrocarpa son muy numerosos $\left(58,67\right.$ vasos por $\left.\mathrm{mm}^{2}\right)$, existiendo diferencias significativas respecto a las otras dos especies. En cuanto al diámetro de los vasos, los valores medios indican que es pequeño $(63,38 \mu \mathrm{m}$ en $J$. excisa, 63,93 $\mu \mathrm{m}$ en $J$. hieronymi y 55,60 $\mu \mathrm{m}$ en $J$. macrocarpa), aunque $J$. macrocarpa se diferencia significativamente por poseer el diámetro medio más chico. Los miembros de vaso son de longitudes cortas en los tres taxones $(304,76 \mu \mathrm{m}$ en $J$. excisa, $280,95 \mu \mathrm{m}$ en $J$. hieronymi y 221,69 $\mu \mathrm{m}$ en $J$. macrocarpa), siendo significativamente menor en $J$. macrocarpa. Respecto al área del xilema/área total del tallo (\%), se encontraron diferencias significativas entre las tres especies: $J$. macrocarpa presentó el menor valor $(9,35 \%), J$. hieronymi presentó un valor intermedio $(14,76 \%)$ y $J$. excisa el mayor porcentaje (24,32\%).
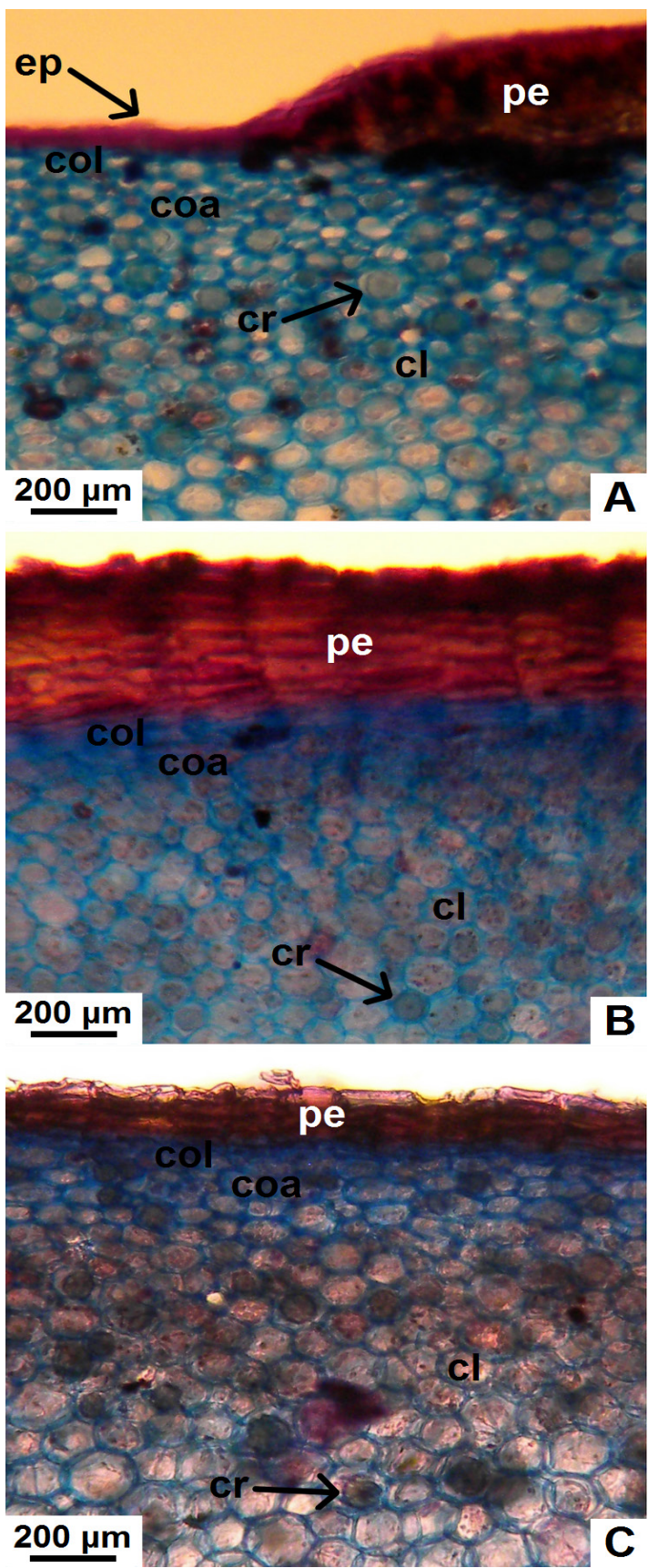

Fig. 3. Detalle de peridermis y corteza interna, en corte transversal de tallo con crecimiento secundario de especies nativas de Jatropha. A, peridermis en formación, colénquima y parénquima en $J$. excisa. B, peridermis, colénquima y parénquima en $J$. hieronymi. C, peridermis, colénquima y parénquima en J. macrocarpa. Abreviatura: cl, clorénquima; coa, colénquima angular; col, colénquima lamelar; cr, cristal; ep, epidermis; pe, peridermis. Figura en color en la versión en línea http://www.ojs.darwin.edu. ar/index.php/darwiniana/article/view/906/1210 

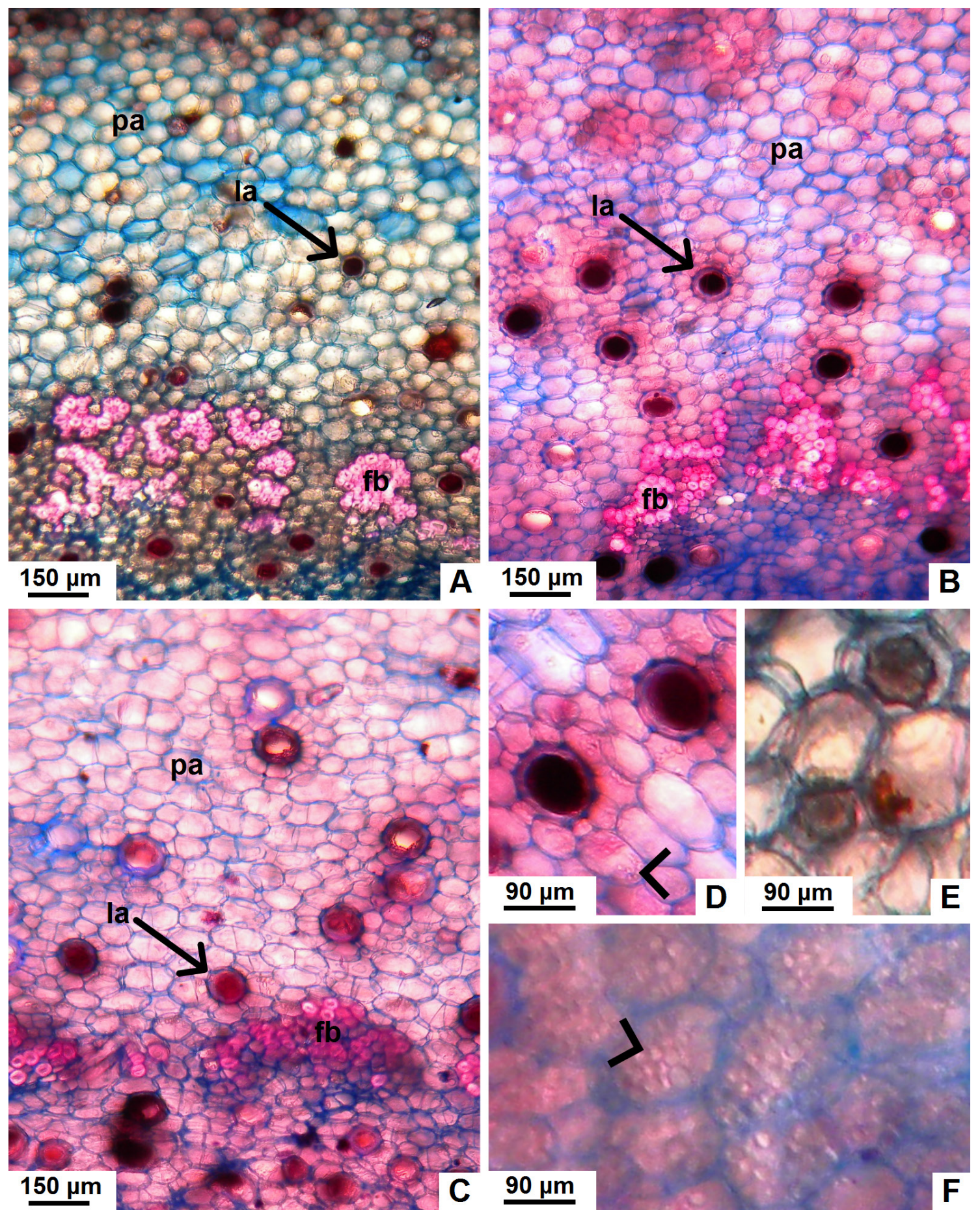

Fig. 4. Detalle de la corteza interna, en corte transversal de tallo con crecimiento secundario de especies nativas de Jatropha. A-C, corteza de $J$. excisa, J. hieronymi y $J$. macrocarpa respectivamente, mostrando fibras perivasculares y laticíferos. D, detalle de los laticíferos de J. hieronymi, donde se observa la pared del mismo y el látex de color pardo oscuro. E, células de $J$. macrocarpa conteniendo cristales (drusas). F, parénquima reservante de almidón en J. macrocarpa. Abreviaturas: fb, fibras; la, laticífero; pa, parénquima. Con punta de flecha se señalan los granos de almidón. Figura en color en la versión en línea http://www.ojs.darwin.edu.ar/index.php/darwiniana/article/view/906/1210 

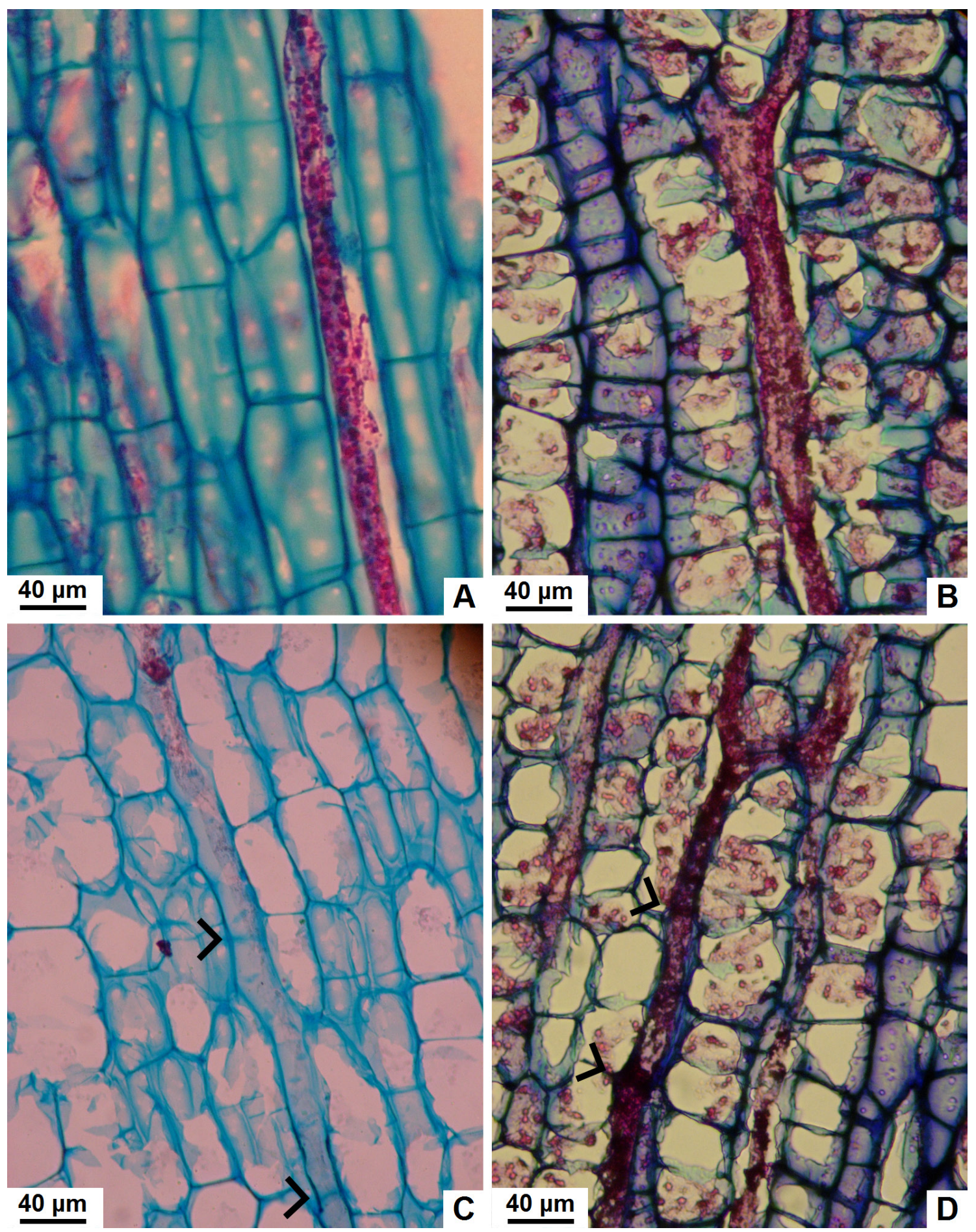

Fig. 5. Tipos de laticíferos observados en tallo con crecimiento secundario de especies nativas de Jatropha, vista longitudinal tangencial. A, no articulado, no ramificado de $J$. excisa. B, no articulado, ramificado de $J$. hieronymi. C, articulado, no anastomosado de J. macrocarpa. D, articulado, anastomosado de J. hieronymi. Con punta de flecha se señalan las articulaciones. Figura en color en la versión en línea http://www.ojs.darwin.edu.ar/index.php/ darwiniana/article/view/906/1210 
En la tabla 1 se resumen los datos obtenidos de estas variables.

\section{Índices analizados}

Jatropha excisa y $J$. hieronymi poseen un IV de 2,29 y 2,24 respectivamente. Por su parte, J. macrocarpa presentó un IV de 0,95, considerablemente menor en relación a las otras dos especies. Según el IM, las tres especies responden a un xilema mesofítico, aunque en $J$. macrocarpa fue considerablemente menor $(210,61)$ en relación al de $J$. excisa $(697,9)$ y $J$. hieronymi $(629,33)$. El IVg es mayor a 1 en los tres taxones (2,88 en J. excisa, 3,1 en $J$. hieronymi y 2,83 en $J$. macrocarpa), lo cual significa que, si bien hay vasos solitarios, la mayoría se encuentran agrupados en el xilema secundario.

\section{DISCUSIÓN}

La morfoanatomía del tallo de las especies analizadas muestra una marcada uniformidad, no sólo en la composición de los tejidos, sino también en la disposición de los mismos, los cuales se distribuyen siguiendo el modelo más común en Euphorbiaceae (Thakur \& Patil, 2012; Webster, 2014). A pesar de que los individuos analizados eran ejemplares adultos, los tres taxones evidenciaron una etapa temprana del crecimiento secundario, caracterizada por xilema y floema secundario en desarrollo, y una peridermis que, en el caso de $J$. excisa, aún estaba en formación. Es importante conocer las etapas tempranas del crecimiento secundario de estas especies ya que pone en evidencia que los meristemas laterales (el cámbium vascular y el felógeno) se desarrollan tempranamente, brindando a las plantas ciertas ventajas que les permiten protegerse en ambientes hostiles (Pérez Cuadra \& Cambi, 2014).

Sólo en $J$. hieronymi y $J$. macrocarpa, el ritidoma se desprendía en láminas papiráceas; la presencia o ausencia de corteza exfoliante es un carácter con implicancia taxonómica (Dehgan, 2012). Los rasgos de la corteza externa han recibido comparativamente menos atención que el xilema en los estudios ecológicos de la resistencia al déficit de agua, pero la evidencia sugiere que su papel podría ser central en la seguridad hidráulica (Loram-Lourenço et al., 2020).

Tabla 1. Análisis de la varianza de caracteres analizados en tallo con crecimiento secundario de tres especies nativas de Jatropha. Los valores representan promedios \pm desvío estándar; los números entre paréntesis son los valores mínimo y máximo observado para cada especie. Letras diferentes muestran diferencias significativas entre especies $(p<0,05)$.

\begin{tabular}{|c|c|c|c|}
\hline Variable & J. excisa & J. hieronymi & J. macrocarpa \\
\hline $\begin{array}{l}\text { Número de vasos por } \\
\text { mm² }^{2}\end{array}$ & $\begin{array}{c}27,63 \pm 23,40 a \\
(0-92,27)\end{array}$ & $\begin{array}{c}28,48 \pm 21,21 \mathrm{a} \\
(0-76,89)\end{array}$ & $\begin{array}{l}58,67 \pm 20,93 b \\
(15,38-107,65)\end{array}$ \\
\hline Diámetro de vasos $(\mu \mathrm{m})$ & $\begin{array}{l}63,38 \pm 14,03 b \\
(36,84-99,47)\end{array}$ & $\begin{array}{l}63,93 \pm 19,42 b \\
(33,16-110,53)\end{array}$ & $\begin{array}{l}55,60 \pm 10,91 \mathrm{a} \\
(36,84-77,37)\end{array}$ \\
\hline $\begin{array}{l}\text { Longitud de elementos } \\
\text { de vaso }(\mu \mathrm{m})\end{array}$ & $\begin{array}{l}304,76 \pm 81,95 b \\
(142,86-471,43)\end{array}$ & $\begin{array}{c}280,95 \pm 77,16 b \\
(114,29-500)\end{array}$ & $\begin{array}{l}221,69 \pm 52,78 a \\
(128,57-357,14)\end{array}$ \\
\hline $\begin{array}{l}\text { Área del xilema/área } \\
\text { total del tallo (\%) }\end{array}$ & $\begin{array}{l}24,32 \pm 4,77 \mathrm{c} \\
(18,81-33,74)\end{array}$ & $\begin{array}{l}14,76 \pm 2,18 b \\
(11,73-18,05)\end{array}$ & $\begin{array}{l}9,35 \pm 2,13 \mathrm{a} \\
(5,78-12,56)\end{array}$ \\
\hline
\end{tabular}



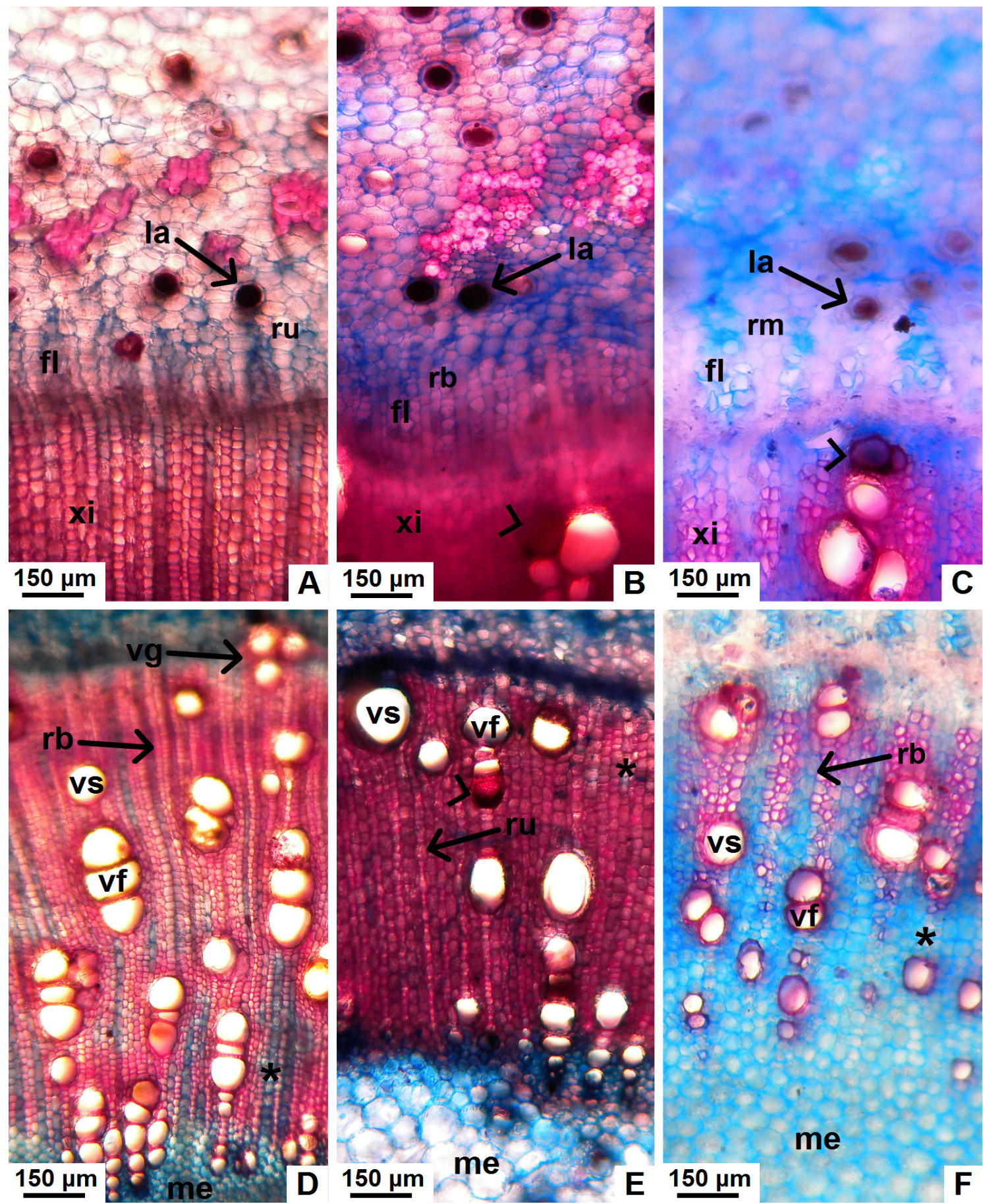

Fig. 6. Tejidos vasculares en tallo con crecimiento secundario de especies nativas de Jatropha, corte transversal. A, floema secundario de $J$. excisa, con radios uni y biseriados. B, floema secundario de $J$. hieronymi con radios uni y biseriados. C, floema secundario de $J$. macrocarpa, con radios multiseriados. D-F, xilema secundario en corte transversal, de $J$. excisa, $J$. hieronymi y $J$. macrocarpa, respectivamente. Abreviaturas: fl, floema secundario; la, laticífero; me, médula; rb, radio biseriado; rm, radio multiseriado; ru, radio uniseriado; vs, vaso solitario; vf, vasos en filas radiales; vg, vasos en grupos; xi, xilema secundario. Con punta de flecha se señala un vaso ocluido. Con asterisco se señalan zonas de parénquima apotraqueal. Figura en color en la versión en línea http://www.ojs.darwin.edu.ar/index.php/darwiniana/article/view/906/1210 


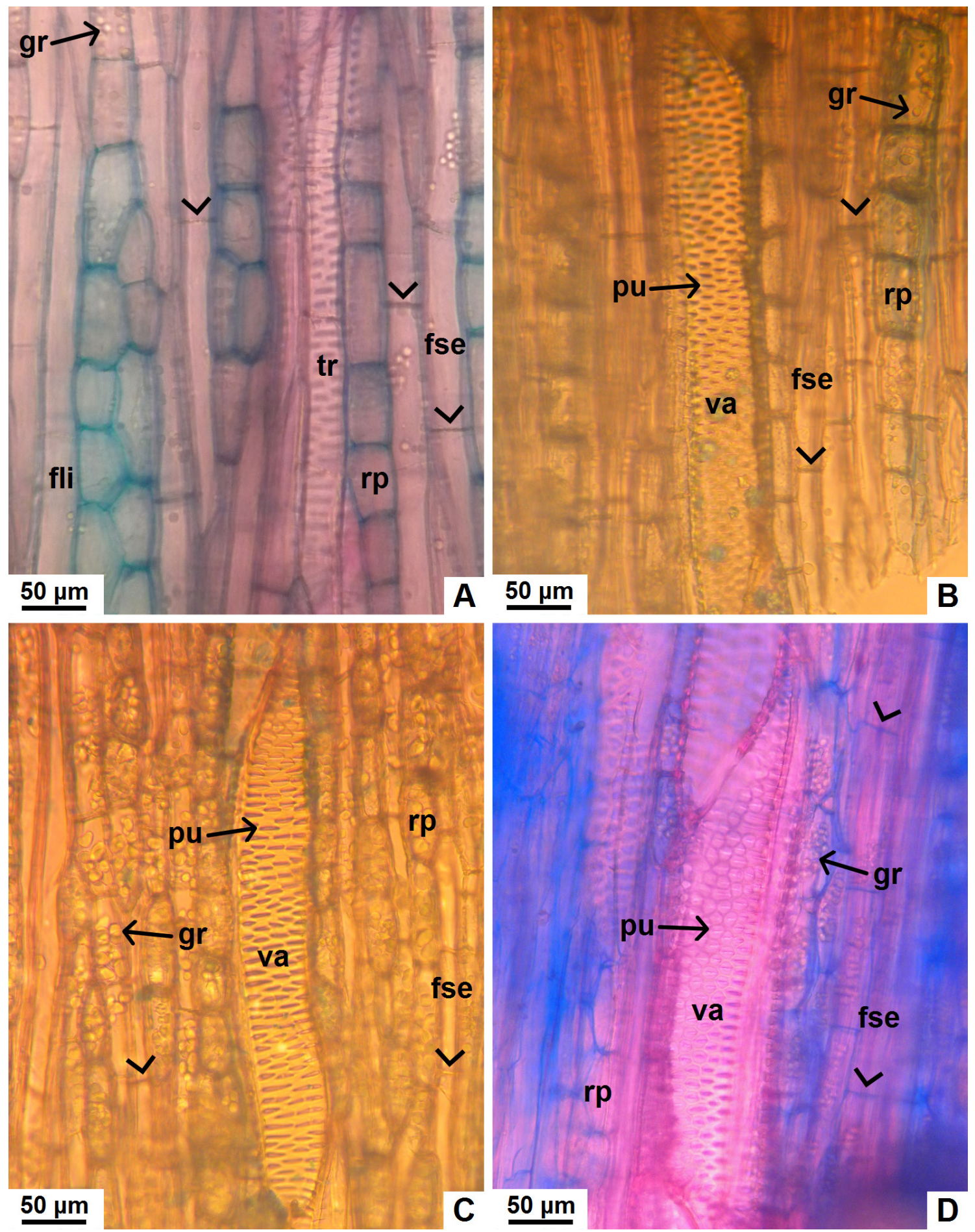

Fig. 7. Xilema secundario en tallo de especies nativas de Jatropha, en corte longitudinal tangencial. A, detalle de traqueida de $J$. excisa. B-D, detalle de vasos de $J$. excisa, J. hieronymi y J. macrocarpa, respectivamente. Abreviaturas: fli, fibra libriforme; fse, fibra septada; gr, granos de almidón; pu, puntuaciones alternas; rp, radio parenquimático; tr, traqueida; va, vaso. Con punta de flecha se señalan los septos de las fibras. Figura en color en la versión en línea http:// www.ojs.darwin.edu.ar/index.php/darwiniana/article/view/906/1210 
La corteza externa generalmente está asociada con la protección al fuego y los patógenos (Rosell, 2016). Sin embargo, la presencia de células con paredes engrosadas y muy suberificadas en la peridermis, como presentaron las tres especies analizadas en este trabajo, provee una cubierta protectora y una barrera contra la pérdida de agua y solutos, que puede contribuir no sólo a una mejor adaptación a las regiones áridas, sino también a un aislamiento térmico contra inviernos helados (Tavecchio et al., 2016).

La corteza interna ancha de estas especies coincide con las observaciones de Thakur \& Patil (2012), quienes estudiaron la anatomía del tallo con crecimiento primario de algunos representantes de la familia Euphorbiaceae. Se ha sugerido que, en plantas xerófitas, una corteza con gran cantidad de estratos celulares puede ser más eficiente para proteger los tejidos vasculares de la sequía u otros daños (Fahn \& Cutler, 1992). El desarrollo de tejidos de sostén, como la presencia de varios estratos de colénquima en las tres especies analizadas, principalmente en $J$. excisa, es un importante indicador de xeromorfismo; ya que le confiere al tallo rigidez estructural, otorgándole resistencia al colapso y desgarramiento debido a la desecación (Beltramini \& Zapata, 2020). Los tres taxones estudiados presentaron varios estratos de clorénquima, lo que les permite seguir llevando a cabo el proceso fotosintético en la corteza; esta característica se da sobre todo en troncos jóvenes, con escasa cantidad de ritidoma (Rodríguez-Calcerrada et al., 2015). La existencia de clorénquima en tallos leñosos fue reportada anteriormente en $J$. curcas (Thomas \& Daniel, 2007). Una gran cantidad de investigaciones, sugieren que la presencia de tallos fotosintetizantes en especies de ecosistemas áridos favorece la supervivencia de las plantas ya que le confieren ventajas fisiológicas, incluyendo ganancia extra de carbono durante períodos de sequía, equilibrio de los costos respiratorios como resultado de la re-asimilación de $\mathrm{CO}_{2} \mathrm{y}$ mayor eficiencia en el uso del agua (Cernusak \& Cheesman, 2015; Ávila-Lovera et al., 2017).
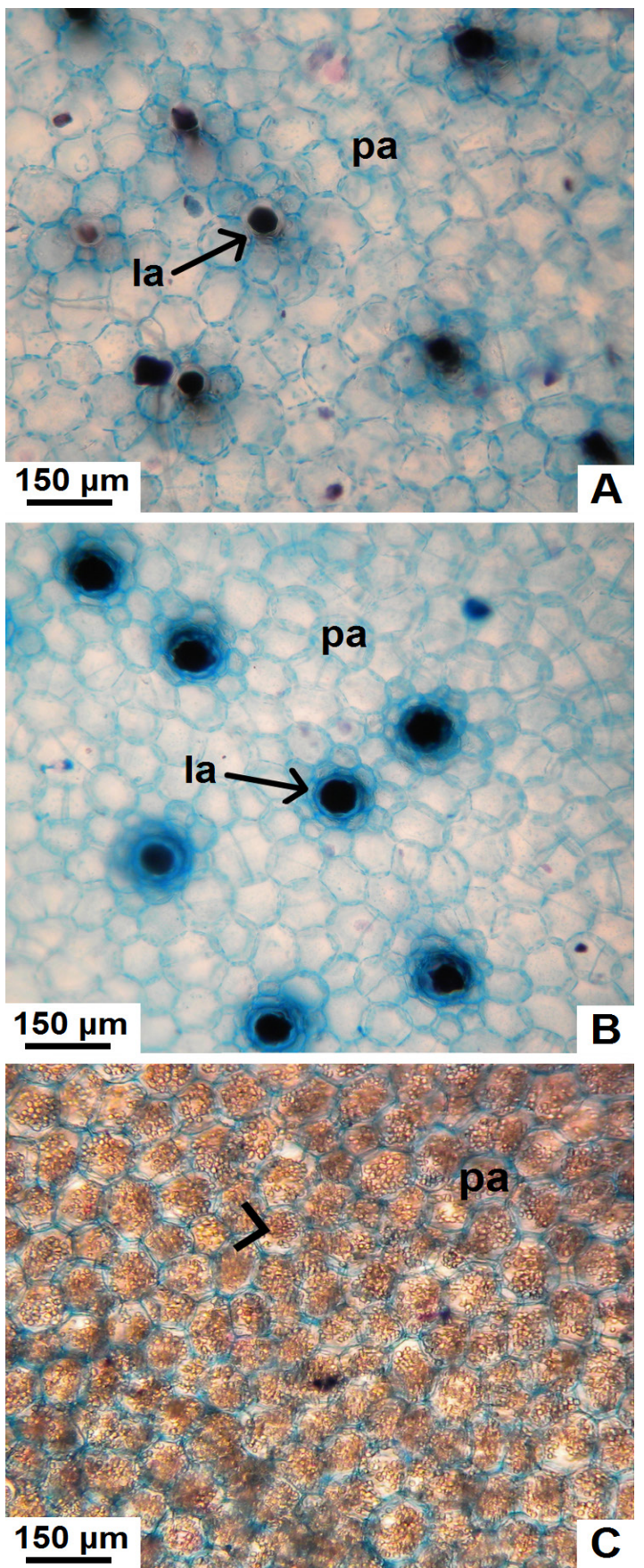

Fig. 8. Detalle de la médula parenquimática, en corte transversal de tallo con crecimiento secundario de especies nativas de Jatropha. A, médula de J. excisa, con laticíferos. B, médula de J. hieronymi con laticíferos. C, parénquima reservante de almidón en J. macrocarpa. Abreviaturas: la, laticífero; pa, parénquima. Con punta de flecha se señalan los granos de almidón. Figura en color en la versión en línea http://www.ojs.darwin.edu. ar/index.php/darwiniana/article/view/906/1210 
La fotosíntesis cortical es particularmente importante en especies de hojas caducas, como las analizadas en el presente trabajo. Esto se ha constatado en varios casos donde se observó que la tasa fotosintética de los tallos es más alta durante la época de ausencia de follaje, debido a un aumento de la incidencia de la radiación solar (Ávila-Lovera et al., 2017; Simkin et al., 2020).

El almacenamiento de almidón es una fuente de reserva energética de extrema utilidad para aquellas plantas que habitan en ambientes adversos, desempeñando un papel en la preservación de las especies xerófitas (Fahn \& Cutler, 1992). Granos de almidón fueron registrados en el parénquima cortical, xilemático y medular de los tallos de J. excisa, J. hieronymi y $J$. macrocarpa, observándose más abundancia en la última especie. La acumulación de almidón en el parénquima del xilema podría proteger a las plantas de la embolia inducida por la sequía, ya que se ha observado en otras especies que la hidrólisis del mismo es esencial en el proceso de recuperación de los elementos conductores afectados (Brodersen \& McElrone, 2013). Tavecchio et al. (2016) reportaron la presencia de abundante almidón en tallos con crecimiento primario de $J$. macrocarpa, y señalaron que esa abundancia podría ayudar a esta especie durante los períodos fríos, manteniendo la concentración osmótica intracelular, por catabolismo de la macromolécula. Por su parte, Malbrán Barros (2018) también detectó granos de almidón en los tallos primarios de $J$. macrocarpa, J. excisa $\mathrm{y}$, en menor cantidad en $J$. pedersenii, especie que habita en el litoral argentino, donde la humedad es mayor. Se ha reportado la presencia de ese carbohidrato en otros representantes del género que habitan en ambientes áridos o semiáridos, como Jatropha maheswarii Subr. \& Nayar y $J$. curcas (Uthayakumari \& Sumathy, 2011; Tavecchio et al., 2016).

En los ambientes áridos, la producción de biomasa vegetal es costosa, por lo tanto, las plantas han desarrollado diversos mecanismos para evitar la pérdida de biomasa causada por la herbivoría o el ataque de microorganismos. Entre estos mecanismos se puede citar la presencia de células contenedoras de cristales y los laticíferos (Fahn, 1986).
En los tres taxones estudiados se encontraron cristales en el parénquima cortical, tal como lo reportó Malbrán Barros (2018) en tallos con crecimiento primario de J. excisa, J. macrocarpa y $J$. pedersenii. Esta sustancia ergástica puede actuar como mecanismo de defensa contra herbívoros e interviene en la regulación de los niveles de calcio dentro de la planta (JáureguiZúñiga \& Moreno Cárcamo, 2004).

Los laticíferos son indicativos del éxito evolutivo en las especies que los presentan, ya que el látex actúa contra la herbivoría, agentes patógenos y posibilita el sellado de heridas (Ramos et al., 2020). En Jatropha se ha documentado la presencia de laticíferos de distintos tipos: articulados, no articulados e idioblásticos (Dehgan \& Craig, 1978). Por su parte, Malbrán Barros (2018) menciona la existencia de laticíferos articulados y no articulados en tallos con crecimiento primario de $J$. excisa, J. macrocarpa y $J$. pedersenii. En relación al ambiente en que crecen las plantas, se ha determinado que la fluidez del látex disminuye drásticamente cuando las mismas están expuestas a la luz solar, siendo más viscoso que el que se produce temprano en la mañana o justo después del anochecer. Esta ocurrencia probablemente esté relacionada con la tasa de transpiración de las plantas, ya que el agua puede atravesar libremente la pared de casi todos los laticíferos (Ramos et al., 2019). Hasta el momento, no se conoce la composición química del látex de las especies nativas, por lo que sería muy interesante llevar a cabo pruebas histoquímicas, que proporcionen información sobre la presencia de metabolitos, demostrando el potencial de las especies como fuente de compuestos biológicamente activos a explorar (Diniz et al., 2013).

En el xilema, no se evidenció tilosis, pero sí la oclusión de algunos vasos con una sustancia parda. Hay estudios que indican que los conductos xilemáticos pueden obstruirse, ya sea por tilosis o compuestos como taninos, gomas o cristales, en épocas de déficit de agua; esas oclusiones ayudan a mantener la presión positiva en el tallo, necesaria para rellenar los vasos embolizados (Kitin et al., 2010; Tng et al., 2018). 
En cuanto a las variables cuantitativas analizadas, las tres especies presentaron vasos numerosos, de longitudes cortas y diámetro pequeño. Estas características son típicas de plantas que habitan regiones áridas y semiáridas permitiéndoles soportar el estrés hídrico. Los elementos conductores cortos son más resistentes al colapso o deformación que los largos, debido al reforzamiento proporcionado por las paredes de los extremos, y confieren mayor seguridad al proceso conductivo. La estrechez de los vasos está correlacionada inversamente con el número de vasos para disminuir la vulnerabilidad a la cavitación (Carlquist, 1977; 2001). Oladipo \& Illoh (2012) midieron variables xilemáticas en el leño de cinco especies de Jatropha que habitan en una región tropical de Nigeria que tiene mayor humedad que la Región Chaqueña y encontraron vasos más largos $(402,56-527,62 \mu \mathrm{m})$ y más anchos $(60,99-89,16 \mu \mathrm{m})$ respecto a lo hallado en este trabajo $(221,69-304,76 \mu \mathrm{m}$ de long. $\mathrm{y}$ 55,60-63,38 $\mu \mathrm{m}$ de diám.). Es de destacar que $J$. macrocarpa se diferenció significativamente de $J$. excisa y $J$. hieronymi por poseer los vasos de longitudes más cortas, más angostos y más numerosos, reuniendo las características más específicas de ambientes xerófitos. La mayor área del xilema/área total del tallo se encontró en $J$. excisa, indicando que facilitaría la conducción de agua, ya que a medida que el porcentaje de ese tejido aumenta, la cantidad de agua transportada es mayor (Sory Toure et al., 2010). Las especies expuestas a una alta incidencia de radiación solar poseen mayores tasas de evapotranspiración; para compensar esa liberación de agua a la atmósfera necesitan un área conductora más grande respecto a plantas con baja incidencia de radiación solar (Aparecido, 2014). Son pocos los trabajos que incluyen la medición del área de xilema al analizar la anatomía del tallo en relación al ambiente (Chui \& Ewers, 1992; Rzepecki et al., 2011). La inclusión de esta variable, junto con otras que consideren distintos aspectos xilemáticos, puede brindar información valiosa en estudios eco-anatómicos, para comprender cómo la anatomía de las plantas influye en la conducción del agua (Aparecido, 2014).
El IVg mayor a 1 en las tres especies representa vasos agrupados en su mayoría. Según la clasificación de IAWA Committee (1989), serían vasos parcialmente solitarios y parcialmente agrupados en múltiples radiales. Este agrupamiento brinda mayor seguridad en la conducción, resistiendo las tensiones de agua de forma más eficaz que los vasos aislados; además, disminuye la posibilidad de que los vasos se tornen inactivos por embolia bajo estrés hídrico, perjudicando seriamente la conducción en la planta (Carlquist, 1977, 2001). El IV de 0,95, en $J$. macrocarpa, indica que dicha especie presenta un número y diámetro de vasos que le brindan resistencia a la sequía. En cuanto a $J$. excisa y $J$. hieronymi, si bien sus IV indicaron vulnerabilidad a la sequía, los valores obtenidos fueron relativamente bajos $(2,29 \mathrm{y}$ 2,24 respectivamente), lo que podría traducirse como una baja vulnerabilidad considerando que algunas especies de regiones húmedas tienen IV tan altos como 73,33 para Chorisia insignis HBK \& K. y 42,50 para Chorisia speciosa A. St.-Hil. (Moglia \& Gimenez, 1998). Montaño Arias et al. (2013) obtuvieron un IV de 3,56 para Mimosa hexandra M. Micheli, que habita en el matorral xerófito de México, y fue considerada como una especie de resistencia intermedia al estrés hídrico. En cuanto al IM, en los tres casos, es mayor a 200, siendo el xilema mesofítico, a pesar de que el valor en $J$. macrocarpa fue solo de 210,61, aproximadamente un tercio del valor obtenido para $J$. excisa y $J$. hieronymi (697,9 y 629,33 respectivamente). Se ha determinado que un xilema mesofítico, en conjunto con valores de IV menores a cinco, tal como ocurrió en las tres especies analizadas en este trabajo, indicaría que los taxa tienen un sistema de conducción seguro y eficaz para el movimiento del agua (Montaño Arias et al., 2013).

Es de importancia resaltar que hasta el momento, no se habían medido variables xilemáticas en tallos de ninguno de los representantes nativos ni se habían relacionado aspectos anatómicos con el ambiente que habitan. La información brindada en este trabajo contribuye al conocimiento de estas 
plantas nativas, $y$ es fundamental si se pretende realizar cultivos a gran escala de estas especies de Jatropha para aprovechar su potencialidad como productoras de biodiesel. Argentina cuenta con importantes ventajas en la producción de materias primas con potencial para la obtención de este combustible. Este país, dispone de una alta dotación de recursos naturales y de amplias condiciones agroecológicas para el cultivo de diversas especies con fines energéticos (Vega, 2010) y, desde hace algunos años, se están desarrollando proyectos con cultivos de gran envergadura de $J$. curcas y $J$. macrocarpa en provincias del Noroeste, como Santiago del Estero y La Rioja (Aiassa, 2009). Las especies nativas de Jatropha analizadas en este trabajo se presentan como cultivos alternativos en regiones áridas o semiáridas del país, no compitiendo por superficie con las oleaginosas tradicionales utilizadas para la obtención de biodiesel (Falasca y Ulberich, 2008).

Este trabajo constituye una primera aproximación al conocimiento de la morfoanatomía del tallo con crecimiento secundario de estas especies nativas, pero aún quedan muchos aspectos por explorar. Futuros estudios anatómicos de las especies nativas de Jatropha, deberían complementar el presente con técnicas específicas, como maceración en leño para determinar características específicas del xilema secundario, pruebas histoquímicas y observaciones con luz polarizada. Estos análisis permitirán profundizar en aspectos de la morfoanatomía e histoquímica de los órganos vegetativos, contribuyendo al conocimiento de estos taxones y sus estrategias para vivir en un ambiente árido.

\section{CONCLUSIONES}

El tallo de las especies analizadas presenta ciertos caracteres anatómicos que son propios de plantas que habitan ambientes xerófitos $y$, que en conjunto, contribuyen a que las mismas puedan desarrollarse a pesar de las escasas precipitaciones y elevadas temperaturas, incluyendo: súber y felodermis con paredes celulares engrosadas; corteza interna con varios estratos celulares; presencia de colénquima; presencia de clorénquima; sustancias ergásticas en corteza, tejido vascular y médula (látex, cristales y granos de almidón); vasos xilemáticos cortos, estrechos, numerosos y agrupados.

Jatropha macrocarpa posee un IV que representa resistencia a la sequía. En $J$. excisa y $J$. hieronymi, el IV no se corresponde con plantas de ambientes secos, aunque los valores no están alejados de lo citado para especies xerófitas. En las tres especies, el IM indica un xilema mesofítico; sin embargo, los valores obtenidos en conjunto con IV menores a cinco, sugiere que los taxones tienen un sistema de conducción seguro y eficaz para el movimiento del agua. Este estudio de anatomía ecológica brinda información novedosa sobre tres especies de importancia biológica, industrial y económica que son potenciales productoras de biodiesel.

\section{AGRADECIMIENTOS}

Las autoras de este trabajo agradecen a la Secretaría de Ciencia y Técnica (SeCyT) de la Universidad Nacional de Córdoba, por proporcionar los fondos necesarios para llevar a cabo el presente trabajo; y a María Teresa Cosa por proveer parte del material utilizado.

\section{BIBLIOGRAFÍA}

Achten, W. M.; L. Verchot., Y. J. Franken, E. Mathijs, V. P. Singh, R. Aerts \& B. Muys. 2008. Jatropha bio-diesel production and use. Biomass and Bioenergy 32(12): 1063-1084.

Aiassa, P. 2009. La Jatropha como cultivo industrial en Argentina. Tesis de grado. Instituto Tecnológico de Buenos Aires, Buenos Aires, Argentina.

Aparecido, L. M. T. 2014. Padrões da área do xilema ativo em espécies florestais amazônicas na região de Manaus (Am). Disertación para optar al título de Maestría en Ciencias en Silvicultura Tropical, área de concentración en Manejo Forestal. Instituto Nacional de Investigaciones de la Amazonía (INPA). Manaus, Brasil. 
Aranda Rickert, A. 2011. Ecología de la dispersión de semillas por hormigas en Jatropha excisa Griseb. (Euphorbiaceae). Tesis doctoral. Universidad de Buenos Aires, Buenos Aires, Argentina.

Aranda Rickert, A.; L. Morzán \& S. Fracchia. 2011. Seed oil content and fatty acid profiles of five Euphorbiaceae species from arid regions in Argentina with potential as biodiesel source. Seed Science Research 21(1): 63-68.

Ávila-Lovera, E.; A. J. Zerpa \& L. S. Santiago. 2017. Stem photosynthesis and hydraulics are coordinated in desert plant species. New Phytologist 216(4): 11191129.

Beltramini, V. S. \& Zapata, R. M. 2020. Adaptaciones morfológicas de la plántula de Ramorinoa girolae (Fabaceae) a condiciones de aridez. Lilloa 57(1): 1-12.

Brodersen, C.R. \& A. J. McElrone. 2013. Maintenance of xylem network transport capacity: a review of embolism repair in vascular plants. Frontiers in Plant Science 4(108): 1-11.

Cabrera, A. L. 1994. Regiones fitogeográficas argentinas, $1^{\text {a }}$ reimpresión, revisión a cargo de W. F. Kugler. Enciclopedia argentina de agricultura y jardinería, tomo 2, fasc. 1. Buenos Aires: Acme. (Publ. orig. 1976).

Carlquist, S. 1977. Ecological factors in wood evolution: a floristic approach. American Journal of Botany 64(7): 887-896.

Carlquist, S. 2001. Comparative wood anatomy: systematic, ecological, and evolutionary aspects of dicotyledon wood, $2^{\text {a }}$ edición. Berlín: Springer.

Cernusak, L. A. \& Cheesman, A. W. 2015. The benefits of recycling: how photosynthetic bark can increase drought tolerance. New Phytologist 208(4): 995-997.

Chui, S. T. \& F. W. Ewers. 1992. Xylem structure and water transport in a twiner, a scrambler, and a shrub of Lonicera (Caprifoliaceae). Trees 6(4): 216-224.

Clérici, S.; J. Aranda, P. Martínez, C. Torchán \& F. Baravalle. 2013. Caracterización morfológica y citogenética de Jatropha excisa, en la ecorregión chaco seco de la provincia de Catamarca. Revista Virtual: Revista Biología en Agronomía 3(1): 24-36.

Consejo Agropecuario del Sur. 2009. Situación de la Jatropha y perspectivas. Red de Coordinación de Políticas Agropecuarias.

Dehgan, B. 2012. Jatropha (Euphorbiaceae). Flora Neotropica Monograph 110. New York: The New York Botanical Garden Press.

Dehgan, B. \& M. E. Craig. 1978. Types of laticifers and crystals in Jatropha and their taxonomic implications. American Journal of Botany 65(3): 345-352.
Demaio, P.; U. O. Karlin \& M. Medina. 2015. Árboles nativos de Argentina. Tomo 1: Centro y Cuyo. Córdoba: Ecoval.

Diniz, R. P.; N. D. Araújo \& M. F. Agra. 2013. Anatomía e histoquímica foliar e caulinar de Jatropha ribifolia (Euphorbiaceae). Libro de resúmenes del $64^{\circ}$ Congresso Nacional de Botânica. Belo Horizonte, Brasil

Di Rienzo, J. A.; F. Casanoves, M. G. Balzarini, L. González, M. Tablada \& C. W. Robledo. 2018. Grupo InfoStat, FCA, Universidad Nacional de Córdoba, Argentina. Disponible en: http://www.infostat.com.ar [consulta julio de 2020].

Fahn, A. 1986. Structural and functional properties of trichomes of xeromorphic leaves. Annals of Botany 57(5): 631-637.

Fahn, A. \& D. F. Cutler. 1992. Xerophytes. Stuttgart: Gebrüder Borntraeger.

Falasca, S. \& A. Ulberich. 2008. Las especies del género Jatropha para producir biodiesel en Argentina. Revista Virtual Redesma 2(1): 1-19.

Fernández Casas, F. J. 2016. Acerca del género Jatropha (Euphorbiaceæ) en Insulindia. Adumbrationes ad Summae Editionem 73: 1-58.

Fernández Casas, F. J. \& J. M. Pizarro Domínguez. 2007a. Otras dos Jatrophce (Euphorbiaceæ) de Paraguay. Adumbrationes ad Summae Editionem 19: 1-32.

Fernández Casas, F. J. \& J. M. Pizarro Domínguez. 2007b. Jatropha hieronymi Kuntze (Euphorbiaceae) nomenclatura, sistemática, morfología y distribución. Adumbrationes ad Summae Editionem 28: 1-28.

Font, F. 2003. Las especies del género Jatropha L (Euphorbiacea, Crotonoideae) en Argentina. Revista del Círculo de Coleccionistas de Cactus y Crasas de la República Argentina 2(1): 4-20.

Giménez, A. M. \& J. G. Moglia. 2003. Árboles del Chaco argentino: guía para el reconocimiento dendrológico. Santiago del Estero: El Liberal.

IAWA Committee. 1989. IAWA list of microscopic features for hardwood identification. E. A. Wheeler, P. Baas \& P. E. Gasson (eds.), IAWA Bulletin n. s. 10(3): 219-332, $4^{\text {a }}$ edición 2007.

Jáuregui-Zúñiga, D. \& A. Moreno Cárcamo. 2004. La biomineralización del oxalato de calcio en plantas: retos y potencial. Revista de Educación Bioquímica 23(1): 18-23.

Kitin, P.; S. L. Voelker, F. C. Meinzer, H. Beeckman, S. H. Strauss \& B. Lachenbruch. 2010. Tyloses and phenolic deposits in xylem vessels impede water transport in lowlignin transgenic poplars: a study by cryo-fluorescence microscopy. Plant Physiology 154(2): 887-898. 
Kraus, J. E.; H. C. de Sousa, M. H. Rezende, N. M. Castro, C. Vecchi \& R. Luque. 1998. Astra blue and basic fuchsin double staining of plant materials. Biotechnic \& Histochemistry 73(5): 235-243.

León, W. J. 2005. Anatomía ecológica del xilema secundario de un bosque seco tropical de Venezuela. Acta Botánica Venezuelica 28(2): 257-273.

Loram-Lourenço L.; F. D. S. Farnese, L. F. D. Sousa, R. D. F. B. Alves, M. C. R. D. Andrade, S. E. D. S. Almeida, L. M. D. F. Moura, A. C. Costa, F. G. Silva, J. Galmés, H. Cochard, A. C. Franco \& P. E. Menezes-Silva. 2020. A structure shaped by fire, but also water: Ecological consequences of the variability in bark properties across 31 species from the Brazilian Cerrado. Frontiers in plant science 10(1): 1718 .

Malbrán Barros, A. 2018. Morfo-anatomía vegetativa en especies de Jatropha (Euphorbiaceae) con especial referencia a las estructuras secretoras. Tesina de grado. Universidad Nacional de Córdoba, Córdoba, Argentina.

Malbrán Barros, A.; V. Cabrera, M. T. Cosa \& M. Matesevach, M. 2016. Anatomía vegetativa y estudios histoquímicos en especies nativas de Jatropha (Euphorbiaceae) con uso potencial para la producción de biodiesel. Libro de resúmenes de la II Reunión Argentina de Jóvenes Botánicos. San Juan, Argentina. pp 140.

Malbrán Barros, A.; V. Cabrera, M. T. Cosa \& M. Matesevach. 2017. Anatomía foliar comparada en especies de Jatropha (Euphorbiaceae) nativas de Argentina. XXXVI Jornadas Argentinas de Botánica. Mendoza, Argentina. Boletín de la Sociedad Argentina de Botánica 52 (Supl): 17.

Moglia, G. \& A. M. Giménez. 1998. Rasgos anatómicos característicos del hidrosistema de las principales especies arbóreas de la región chaqueña argentina. Investigación Agraria. Sistemas y Recursos Forestales 7(1-2): 53-71.

Moglia, J. G. \& C. R. López. 2001. Estrategia adaptativa del leño Aspidosperma quebracho blanco. Madera y Bosques 7(2): 13-25.

Montaño Arias, S. A.; S. L. Camargo Ricalde \& C. D. L. P. Pérez Olvera. 2013. Ecoanatomía de los elementos de vaso de la madera de cinco especies del género Mimosa (Leguminosae- Mimosoideae). Botanical Sciences 91(1): 1-10.

Oladipo, O. T. \& H. C. Illoh. 2012. Comparative wood anatomy of some members of the genus Jatropha (Euphorbiaceae) found in Nigeria. Phytologia Balcanica 18(2): 141-147.
Pérez Cuadra, V. \& Cambi, V. N. 2014. Ocurrencia de caracteres anatómicos funcionales foliares y caulinares en 35 especies xero-halófilas. Boletín de la Sociedad Argentina de Botánica 49 (3): 347-359.

Ramos, M. V.; D. Demarco, I. C. da Costa Souza \& C. D. $\mathrm{T}$ de Freitas. 2019. Laticifers, latex, and their role in plant defense. Trends in plant science 24(6), 553-567.

Ramos, M. V.; C. D. T. Freitas, F. S. Morais, E. Prado, M. C. Medina \& D. Demarco. 2020. Chapter one: Plant latex and latex-borne defense, en R. Nawrot (ed.), Advances in Botanical Research. Latex, laticifers and their molecular components: from functions to possible applications: Volumen 93, pp. 1-25. London: Academic Press.

Rasband, W. S. 2018. ImageJ, U. S. National Institutes of Health, Bethesda, Maryland, USA. Disponible en: http://imagej.nih.gov/ij [consulta febrero de 2021].

Rodríguez-Calcerrada, J.; R. Salomón \& L. Gil. 2015. Transport and recycling of $\mathrm{CO} 2$ inside trees: factors complicating the estimation of wood respiration through $\mathrm{CO} 2$ radial efflux. Bosque (Valdivia) 36(1): 5-14.

Rosell J. A. 2016. Bark thickness across the angiosperms: more than just fire. New Phytologist 211(1): 90-102.

Rzepecki, A.; F. Zeng \& F. M Thomas. 2011. Xylem anatomy and hydraulic conductivity of three cooccurring desert phreatophytes. Journal of Arid Environments 75(4): 338-345.

Sharma, S. K. \& H. Singh. 2012. A review on pharmacological significance of genus Jatropha (Euphorbiaceae). Chinese Journal of Integrative Medicine 18(11): 868-880.

Simkin, A. J.; M. Faralli, S. Ramamoorthy \& T. Lawson. 2020. Photosynthesis in non-foliar tissues: implications for yield. The Plant Journal 101(4): 1001-1015.

Sory Toure, A.; R. Nieto Ángel, J. E. Rodríguez Pérez, A. F. Barrientos Priego, L. A. Ibáñez Castillo, E. Romanchik \& C. A. Núñez Colín. 2010. Variación anatómica del xilema en tallo de cultivares de tomate injertados en un tipo criollo. Revista Chapingo Serie Horticultura 16(1): 67-76.

Tavecchio, N.; H. Reinoso, M. Ruffini Castiglione, C. Spanò \& H. E. Pedranzani. 2016. Anatomical studies of two Jatropha species with importance for biodiesel production. Journal of Agricultural Science 8(9): 84-94.

Thakur, H. A. \& D. A. Patil. 2012. Anatomy of stem in some Euphorbiaceae -II. Journal of Experimental Sciences 3(3): 39-44. 
Thomas, S. \& M. Daniel. 2007. Studies on pharmacognosy and phytochemistry of Jatropha curcas Linn and Jatropha gossypifolia Linn., en (ed.) Daniel, M., Arya, A. \& V. M. Raole, Herbal Technology: Recent Trends and Progress, pp. 155-170. Scientific Publishers. India.

Tng, D. Y. P.; D. M. G. Apgaua, Y. F. Ishida, M. Mencuccini, J. Lloyd, W. F. Laurance \& S. G. W. Laurance. 2018. Rainforest trees respond to drought by modifying their hydraulic architecture. Ecology and evolution 8(24): 12479-12491.

Uthayakumari, F. \& M. Sumathy. 2011. Pharmacognostical studies on the endemic medicinal plant Jatropha maheswarii Subr. \& Nayar (Euphorbiaceae). International Journal of PharmTech Research 3(4): 2169-2174.

Vega, O. 2010. Atlas de la Agroenergía y los biocombustibles en las Américas: II Biodiesel. IICA, Programa Hemisférico en Agroenergía y Biocombustibles, San José, Costa Rica.
Wang, T. \& S. N. Aitken. 2001. Variation in xylem anatomy of selected populations of lodgepole pine. Canadian journal of forest research 31(11), 20492057.

Wassner, D.; A. Larran \& D. Rondanini. 2012. Evaluation of Jatropha macrocarpa as an oil crop for biodiesel production in arid lands of the Dry Chaco, Argentina. Journal of Arid Environments 77: 153-156.

Webster, G. L. 2014. Euphorbiaceae, en K. Kubitzki (ed.), The Families and Genera of Vascular Plants. Flowering Plants. Eudicots.: volumen 10, pp. 51-216. Berlín: Springer.

Zarlavsky, G. E. 2014. Histología Vegetal: técnicas simples $y$ complejas. Buenos Aires: Sociedad Argentina de Botánica.

Zuloaga, F. O.; M. J. Belgrano \& C. A. Zanotti. 2019. Actualización del catálogo de plantas vasculares del Cono Sur. Darwiniana, nueva serie 7(2): 208-278. DOI: https://doi.org/10.14522/darwiniana.2019.72.861 